\title{
0 mundo como vontade de representação... no Piauí
}

//////////////I//I Tunico Amancio ${ }^{1}$ 


\section{Resumo}

Cícero Filho é um jovem cineasta piauiense, com uma longa carreira na realização de curtas e longas-metragens, que nunca chegaram formalmente aos circuitos de exibição do Sudeste do país. Pouco importa, porque Cícero é um fenômeno local, muito conhecido no eixo Piauí/Maranhão, com filmes que empolgam multidões e são exibidos por toda parte, aonde o cinema comercial nem sempre chega. Suas principais armas são seu profundo conhecimento da dramaturgia popular e seus métodos de produção e difusão dos filmes.

\section{Palavras-chave}

Cinema contra-hegemônico, cinema alternativo, cinema do Piauí.

\section{Abstract}

Cícero Filho is a young film director from Piauí with a long filmmaking career, including short and feature films which has never been seen outside the North/Northeast regions of Brazil. It does not matter, because Cícero is a local phenomenon, well known in the region of Piauí/Maranhão, with films that excite crowds and are displayed everywhere where the commercial cinema is not always available. Cicero's main particularities are the deep knowledge of popular drama and its methods of production and film distribution.

\section{Keywords}

Counter-hegemonic cinema, alternative cinema, Piauî́s cinema. 


\section{Liberdade ainda que tardia}

Entre as inquietações políticas de um grupo de realizadores, produtores e pesquisadores reunidos por ocasião da $14^{\mathrm{a}}$ Edição da Mostra de Cinema de Tiradentes, em janeiro de 2011, encontra-se a reivindicação de políticas públicas estimulantes e que valorizem a diversidade e a inclusão dos múltiplos "Brasis". Essa preocupação tomou a forma de um manifesto, intitulado exatamente "Carta de Tiradentes", assinado por um contingente expressivo de agentes cinematográficos vindos de algumas partes do país. A composição dessa delegação militante de nove Estados, com seus respectivos signatários - 44 do Rio de Janeiro, 23 de Minas Gerais, 13 de Pernambuco, 9 do Ceará, 7 do Rio Grande do Sul, 6 de São Paulo, 5 da Bahia e apenas um representante do Amazonas e um do Paraná (CARTA DE TIRADENTES, 2011) - , é sintomática do quanto ainda falta para que se articulem as unidades federativas brasileiras e para que tenham voz outros projetos que não aqueles associados ao novíssimo cinema brasileiro ou mesmo ao cinema de guerrilha, que ocupam atualmente a atenção dos olhares mais visionários. Visionários e críticos apenas preocupados com uma modernidade problemática.

Mesmo uma leitura desatenta notará a ênfase ao mercado presente no manifesto - questões que vão da concentração geográfica e política da produção à existência de novos modelos de negócio, passando pela ampliação da produção e do consumo de nossos bens culturais em todas as regiões, assim como pela 
necessidade de maior visibilidade internacional dos filmes brasileiros, ou ainda pela afirmação da vida útil de tais obras num circuito alheio àquele da exibição convencional. Obras que estão em festivais, mostras, cineclubes, salas de aula, computadores, camelôs - em cidades que nem salas de exibição possuem. Finalmente, um cinema que, agora, precisa ser entendido em sua importância democratizante e simbólica, como diz o texto.

Sem a menor delegação de voz para isso, mas utilizando os recursos da retórica, um bocado de ironia e uma informação preliminar para conquistá-la, com o necessário distanciamento, ouso sugerir que se pensem os efeitos de uma "Carta de Teresina”, em que um outro motor cinematográfico ousasse também demonstrar seu potencial de novidade, de invenção; que revelasse novos agentes e novas paisagens emergentes no cenário audiovisual nacional.

Guardemos como pano de fundo a explosão da produção audiovisual brasileira contemporânea, de matriz cinematográfica, motivada pela maior disponibilização dos meios digitais envolvidos no processo. Um incremento que encontra eco em algumas políticas públicas (mais no passado recente que no presente, já sintoma de um provável redirecionamento), no acolhimento em certos festivais e até mesmo na academia, embora nos três segmentos sua aceitação seja condicionada por uma eleição hierarquizante que defende nichos de gosto como universais e democráticos, não raras vezes amparados em frágeis (ou questionáveis) critérios e estruturas de seleção e confirmação.

Por isso, pensei em trazer à baila um interessante estudo de caso, vindo do Piauí. E daí a razão ardilosa de uma hipotética "Carta de Teresina". Antes de tudo, devo esclarecer que foi o assunto que veio à minha mão, casualmente, numa prova cabal do caráter da imponderabilidade deste artigo.

Brasília tem uma feira de importados - que se chamava, antigamente, Feira do Paraguai — , onde se compram excelentes cópias piratas de DVD. Foi lá, enquanto eu buscava inocentemente um eletrodoméstico qualquer, que chegou às minhas mãos um filme chamado Ai que vida 3, produção da TVM, dirigido por 
Cícero Filho, que trazia na contracapa a informação de que fora produzido em São José do Piauí, através de uma iniciativa do pastor Roberto Borges. O DVD contava a história da superação e da fé de Joaquim e Diná, interpretada por 17 jovens atores da cidade. Três trechos de resenha legitimavam a obra - vindos de órgãos como Leitura Crítica, Jornal Meio Norte e Diário do Povo do Piauí, tão desconhecidos para mim como seus autores. Mas um deles dizia exatamente que, com esse filme, "o cineasta Cícero Filho desmistifica a idéia de que o cinema está restrito a grandes produtoras nacionais ou hollywoodianas", e esse argumento me ganhou. O suficiente para me fazer participar do ato ilícito de compra de um perigoso artefato cultural estendido na banca do quiosque brasiliense. Mesmo com medo de que caísse sobre mim a fúria da Justiça brasileira, tão atuante quando se trata do pequeno transgressor, comprei o DVD, curioso pelo fato de o filme ser um produto do Piauí, de ele ser o terceiro de uma série - um sequel, termo digno de toda a sofisticação com que meu amigo Pedro Curi lida com o assunto e, finalmente, por ser produzido por um pastor, para a juventude. Três elementos bastante curiosos. Comprei-o sorrateiramente e levei-o para casa, onde tive a decepção de perceber que comprara gato por lebre. Na verdade, o filme se chamava Marcas do passado e, duplo engano, era um desenvolvimento da história do outro filme, do qual se originava. O dado mais clarificador era que o diretor era mesmo Roberto Borges, o tal pastor da contracapa, e que seus familiares ocupavam muitos cargos na produção, principalmente as mulheres, Débora, Sarah e Roberta, que eram acompanhadas pelas participações especiais de Solange e Ismael Borges, caracterizando um grande empreendimento familiar.

Com a curiosidade atiçada pelo engano a que fora levado, procurei Cícero Filho na internet e me deparei com várias notícias sobre ele, um blog ativo e mesmo uma participação sua no programa de Jô Soares, na TV Globo: descobri um garoto novo e empolgado com cinema, além de aprender que o filme fora um estrondoso sucesso de público. Mandei-lhe uma mensagem, comprei oficialmente seus filmes recentes por via postal e tomei contato com o maravilhoso mundo do cinema de fronteira. De fronteira num sentido literal e figurado, como se verá. 


\section{Lá e cá}

De fronteira, porque, antes de qualquer coisa, Cícero Filho funciona no entorno geográfico Maranhão/Piauí, transitando entre ambos os Estados e produzindo com recursos e permutas amealhados em um lado e em outro. Um trânsito que tem a ver com sua formação nasceu no Maranhão, em Poção de Pedras, terra do compositor João do Vale, aquele do Carcará, que Bethânia gravou, mas se formou em jornalismo no Piauí, onde também tem uma base de produção.

De fronteira também porque os filmes de Cícero Filho são produzidos no esquema mais artesanal possível - e há histórias deliciosas a serem contadas a esse respeito - , e ele confessa inclusive que boa parte da sua obra foi feita com câmera miniDV e equipamento de luz e de som emprestados, ao mesmo tempo em que ele se vale das mais modernas tecnologias de difusão para chamar a atenção sobre seu trabalho. O mecanismo de promoção do diretor/empreendedor é impecável, contando com um sistema oficial de venda de seus produtos também pela internet. Se ele não funciona integralmente, entregue à pirataria, não é por conta do projeto amplo de produção/distribuição, mas pela falta de controle de produtos de tal natureza.

Finalmente, os filmes de Cícero são uma zona de fronteira entre uma postura autoral e o assentamento no mais canônico registro narrativo do cinema. Ele decupa, usa planos e contraplanos, pausa com poentes e paisagens, reforça e intensifica climas, melodramatiza situações, potencializa traços cômicos, enquanto detém todo o processo de produção, roteiriza, dirige, fotografa e edita seus filmes; trabalha com a mesma equipe mínima, com poucas variações; e pretende imprimir sua marca pessoal em cada filme que realiza.

Ai que vida (2008), seu filme mais conhecido, é certamente primitivo em sua busca de uma linguagem moldada pela eficiência narrativa, diluindo e regionalizando a massa quase sempre homogênea de recursos e efeitos dramáticos e traços temáticos difundidos via tevê. Para a realização do trabalho, Cícero Filho contou com seu capital de relações sociais como autor/produtor e daí construiu um star system próprio, baseado em alguns tipos bem demarcados. Outro dos ingredientes capazes de promover uma 
2. Cineasta e jornalista do Piauí. Cf.: "Monteiro Júnior aborda velhice sob ótica feminina”. Disponível em: http://www.acessepiaui.com. br/entretenimento/monteiro-jnior-aborda-velhice-sob-a-ticafeminina/10401.html. Acesso em: 9 set. 2011.

3. Povo favela (1978), Pai herói (1980), Relógio do sol (1981), Espaço marginal (1981), O pagode de Amarante (1985), Dia de passos (1985) e Da Costa e Silva (1985).

4. Quem são os mestres? (2008).

5. O cine Rex e nós (2007) e Um homem sem uma câmera (2007).

6. No meio do caminho (2004), Insone (2005), A noite e a cidade (2005) e Dona Maria (2010).

7. O confidente (2005). imediata empatia com seu público potencial foi a exploração da fala e da paisagem local, incorporadas ao entrecho dramático de maneira incisiva, demonstrando a extensão de seu pertencimento àquele universo cultural.

Mas, mais que tudo, foi capaz de montar um extraordinário sistema de difusão da obra, garantindo sua circulação pelas comunidades carentes do espetáculo cinematográfico tradicional, composto de tela, projetor e cadeira.

\section{O mundo da representação no Piauí}

Segundo o jornalista e cineasta Monteiro Júnior ${ }^{2}$, o cinema chegou ao Estado em 1901, mas a produção de filmes começou tardiamente, nos anos 70, com um curta feito pelo grupo do jornal Grama, chamado Adão e Eva do paraíso ao consumo, saído de uma entrevista de Torquato Neto (1944-1972), um dos piauienses mais ilustres. Em 1970, o grande letrista e versejador tropicalista já dizia que "cinema é um projetor funcionando, projetando imagens em movimento sobre uma superfície qualquer. É muito chato. O quente é filmar" (apud CINEMA, 2011). Nesse momento, foram feitos alguns filmes curtos, entre eles, Davi a guiar (de Durvalino Couto Filho) e Porenquanto (de Carlos Galvão), além de Terror da vermelha, de 1972, do próprio Torquato, assim como algumas animações de Arnaldo Albuquerque. Guru das sete cidades (1972, do friburguense Carlos Bini) foi filmado no Piauí e levou à produção da paródia local Guru das sexys cidades, de Noronha Filho. Ainda nos anos 70, o grupo Mel de abelha, ligado ao cineclube Teresinense, realizou sete curtas ${ }^{3}$, filmes que bebiam na fonte do cinema marginal, talvez pela estetização da precariedade de recursos, mais oportuno que os outros programas artísticos que dominavam a cena cinematográfica do Brasil. Um longo período de baixa produtividade vai ser suplantado a partir de 1994, quando Douglas Machado filma o curta A ponte e, em 2001, roda seu longa Cipriano, trazendo à luz um contingente de jovens realizadores. Eles são Dalson Carvalho ${ }^{4}$, Alan Sampaio ${ }^{5}$, Monteiro Júnior ${ }^{6}$ e Aristides de Oliveira, além de Antonio José Fontinele ${ }^{7}$, Douglas 
8. Um corpo subterrâneo (2007).

9. Corpos humanos (2007) e Capivara (2005).

10. Kátia (2011).

11. Cf.: HOLANDA, K. (2008, p. 147-151).

12. Cf. Dados constantes do Portal Fiel. Disponível em: http:// www.portalfiel.com.br/entrevista. php?id=2-entrevista-com-kesiamesquita.html. Acesso em: 11 set. 2011.
Machado $^{8}$, Karina Matos ${ }^{9}$ e Karla Holanda ${ }^{10}$, entre diversos outros. ${ }^{11}$ Alguns contam com investimento de verbas públicas via editais. E a visibilidade dessa produção é quase sempre tímida.

Quem vai se revelar definitivamente um sucesso de público é Cícero Filho e seus blockbusters Entre o amor e a razão (2006) e Ai que vida (2008), demonstrando o quanto seus filmes angariam a simpatia das plateias locais.

\section{Os filmes de sucesso}

\section{Entre o amor e a razão (2006)}

Claudia e Elizeu vivem uma história de amor, à revelia da rica mãe adotiva da moça, que quer para ela uma vida melhor. Abandonando tudo, Claudia tem três filhos com Eliseu, que deixa sozinho o povoado onde moram, no interior do Maranhão, e vai tentar a sorte em Teresina. Passando por várias privações, Claudia acaba morrendo num incêndio com o filho mais novo, sem que Elizeu saiba de nada. Os filhos são adotados pela avó, que, depois de muita disputa jurídica, perde a tutela para o pai, que retornara, doente e saudoso da família. Mas ele morre antes de conseguir a guarda, e as crianças ficam com a avó paterna, que denuncia em juízo as falcatruas feitas para a adoção das crianças. Tematicamente, o filme se assenta na questão do êxodo rural, nas perversidades do sistema jurídico e, naturalmente, no peso do amor e da família. A narrativa utiliza de modo eficiente a cartilha do melodrama, explicitada a partir do uso correto da escala de planos canônica, que é pontuada por poentes e planos de paisagem, establishing shots que definem um ritmo para a história e demarcam claramente o contexto e a posição de objetos e personagens. O uso do flashback é dramaticamente motivado e impressiona pela concisão, assim como as poucas elipses utilizadas. Um clipe musical, ilustrando a canção que repete o título do filme, relaciona a produção à estrutura fonográfica local. Késia Mesquita é a intérprete - um nome conhecido na cena gospel evangélica do Piauí ${ }^{12}$. Os atores são amadores, à exceção de Anchieta Cardoso, jornalista da capital que faz o protagonista masculino. 
As gravações foram feitas em Teresina, em Poção de Pedras (cidade natal do Cícero) e nos povoados de Barro Vermelho e Moradinha, no interior do Maranhão.

\section{Ai que vida (2008)}

Em Poço Fundo, fictícia cidade nordestina, o prefeito, Zé Leitão, e a vereadora Xica do Poço programam sua reeleição a um mandato assentado na corrupção. Prova disso é o sistema de venda superfaturada de caixões à prefeitura pela funerária local, administrada pelo vereador Paixão. Este último é casado com Cleonice e tem três filhos: o bonitão Valdir, a apagada Vanderléia e o homossexual Vanderlei. Valdir mantém relações sexuais com a primeira-dama, uma mulher volúvel que só pensa em sexo e dinheiro. O terceiro núcleo dramático é composto pela dançarina Charlene, que namora o riquinho Gerald. Valdir tem Romeu como amigo e confidente e, em simetria, Charlene tem a escandalosa Mona. O elemento deflagrador da consciência política da região vai ser a morte do neto de uma camponesa, por falta de médico no hospital e pelo uso de um remédio vencido, dado pelas autoridades - que vão, inclusive, fornecer o caixão superfaturado. Nesse ínterim, Charlene encontra Valdir, e ambos prestam juntos serviços voluntários na Casa de Taipa, organização beneficente para crianças pobres.

Por conta da criança morta sem ajuda, Cleonice da Cruz Piedade, mulher do vereador Paixão, se rebela e se candidata ao cargo de prefeita, com um discurso moralizante. No final, o casal se encontra, depois que se desfaz o casamento de Charlene e Gerald, e ela assume Valdir como seu verdadeiro amor. A mulher do vereador é eleita, desfazendo a rede de corrupção da cidade.

A $i$ que vida faz uma veemente crítica de costumes sob a aparência de uma comédia amalucada. Expõe políticos ao ridículo, denuncia as estruturas de corrupção, apontando para a necessidade de uma faxina política e de atenção ao eleitorado pobre do interior, desarticula a composição tradicional da família, zomba das relações conjugais hierarquizadas e marcadas pela dependência, ao mesmo 
tempo que valoriza o papel da mulher na sociedade. Ele se vale de um humor quase pastelão, com caretas, trejeitos de personagens e correrias, situações ambíguas ou francamente românticas, em tudo demarcando um rígido limite entre o bem e o mal. O que faz, entretanto, a característica maior do filme é o tratamento diferenciado do bordão "Ai que vida", usado para exprimir as mais variadas e distintas situações. A expressão do bordão é amplificada pelo uso da música tonitruante que acompanha e pontua os momentos cômicos do filme. A música-tema, também composta por Cícero e interpretada por Lilly Araújo e Dalmir Filho, alavancou o filme e o antecedeu em sua carreira de sucesso em muitos dos lugares onde ele foi exibido.

As filmagens foram feitas em Amarante e Teresina, no Piauí, e em Esperantinópolis, Timon e São Francisco do Maranhão, no Maranhão, além de Poção de Pedras. Os atores e os técnicos foram pessoas das próprias comunidades, repetindo alguns poucos de Entre o amor e a razão. O filme teve um custo total de $\mathrm{R} \$ 30 \mathrm{mil} \mathrm{e}$ contou com o apoio do governo do Piauí e de algumas empresas.

\section{Cícero e a vontade de representação ${ }^{13}$}

13. Entrevista concedida ao autor em 4 jul. 2011.
Cícero faz filmes desde os 12 anos e computa mais de duas dezenas deles em sua carreira, entre curtas e longas. Começou com o filminho $O$ super filho, em que também atuava, e acaba de produzir Flor de abril, um longa-metragem de mais de duas horas de duração, em lançamento neste ano de 2012 por todo o Brasil. Já tem no gatilho o próximo trabalho: Babaçu Love, uma comédia musical. Transita entre vários gêneros e produziu títulos curiosos como O assassino da torneira aberta, A dama de preto, Adeus cabaça! ou Dê uma xanxa ao amor. Seu cinema é um empreendimento familiar, encabeçado por ele, envolvendo os pais e os irmãos, em suas horas de folga. Sua mãe foi candidata a vereadora, seu pai foi um dos pioneiros do sistema de comunicação do Estado do Maranhão e vendia antenas parabólicas, do que resultou um bom relacionamento com as prefeituras da região. Esse fato justifica a penetração dos filmes de Cícero em boa parte do Nordeste. 
Se os filmes de Cícero se caracterizam por uma certa ingenuidade popular, o mesmo não se pode dizer do esquema em que mais recentemente eles são produzidos; esquema marcado pela interconexão entre política, religião, tecnologia e marketing. Se nada disso anula ou determina o sucesso dos filmes, esses elementos são certamente um importante fator a ser considerado. Porque é na interface entre a moralidade evangélica e a reivindicação política que se moldam suas tramas - que, como parte do processo de produção de identificação, reivindicam um pressuposto neorrealista de interpretação espontânea, buscando para os personagens os atores naturais capazes de uma prosódia verossímil e particular. Essa identificação é adensada pela utilização da paisagem local, de modo realista, reafirmando os laços da ficção com o universo vivido. A música é o terceiro elemento a consolidar a particularidade do contexto do público-alvo potencial - do hino evangélico ao forró, recorrendo aos valores emergentes na estrutura fonográfica da região. Mas, definitivamente, é na disponibilização do produto diretamente a seus consumidores que a estratégia de Cícero parece mais exitosa. Isso acontece pela via direta, através das sessões e caravanas organizadas pelo interior dos Estados do Piauí e do Maranhão, e também por conta do frenesi provocado pela intensa pirataria que envolveu o seu produto mais conhecido.

Ai que vida, segundo o depoimento do realizador ao programa

14. Site, sobre a sala do cinema, em que se fala do lançamento do filme Entre o amor e a razão. Disponível em: http://www.cultura.ma.gov.br/ portal/ccocf/index.php?page $=$ cine_ praia_grande.

Acesso em: 11 set. 2011.

15. Cf.: Matéria de Diógenes de Macedo, intitulada "Filme piauiense 'Ai que vida' é sucesso de público”. Disponível em: http://www. overmundo.com.br/overblog/filmepiauiense-ai-que-vida-e-sucesso-depublico. Acesso em: 11 set. 2011. Estúdio Móvel, da TV Brasil ${ }^{14}$, foi visto no Cine Praia Grande de São Luís, na semana de lançamento, por exatos 4.850 espectadores, considerado um bom público para uma produção local. Em matéria do site Overmundo, segundo a direção do Cine Riverside, de Teresina, o filme alcançou a marca de mil espectadores em menos de uma semana, fazendo em sete dias o que o americano Harry Potter não fez em um mês de exibições, em fala atribuída ao diretor do cinema ${ }^{15}$. E, segundo os dados fornecidos pelo próprio Cícero Filho, a recepção no interior durante o ano de 2010 foi igualmente espetacular: no Maranhão, com sessões pagas a R \$ 2,00 o ingresso, em exibições normalmente apoiadas pelas prefeituras em lugares públicos, abertos ou fechados, a audiência foi de 55.606 pessoas - em cidades como Riachão, Pio XII, Pedreiras, Timão, 
16. Correspondência eletrônica trocada com o diretor, em 4 jul. 2011.

17. Entrevista concedida pelo autor em 2 jun. 2011.

18. Cf.: Diversos depoimentos. Disponíveis em: http://l80graus. com/amarante; Virgilio Queiroz, ator http://www.overmundo.com. br/overblog/filme-piauiense-emdetalhe/; Diógenes Macedo, corroteirista e direção de arte http:// www.portalaz.com.br/noticia/ grande_dirceu/142321/. Acesso em: 13 out. 2011.

19. Cf.: Trabalho de inglês: cenas do filme Entre o amor e a razão regravadas. Disponível em: http://www.youtube.com/ watch? $\mathrm{v}=$ cbsaxX7zmgY. Acesso em: 8 jun. 2011.
Barra do Corda, Dom Pedro e Balsas. No Piauí, foram 23.887 pagantes, em exibições nas cidades de Teresina, Amarante, Castelo do Piauí, Pedro II e Campo Maior. Já em Palmas, no Tocantins, foram 790 pagantes. Os dados são um registro não muito completo do que Cícero chama de seu cinema itinerante: sessões sempre intermediadas pelo poder político local. ${ }^{16}$ Segundo o diretor, até em tribos indígenas o filme foi exibido.

Essa disponibilização do produto é mobilizada por um enorme esforço de vendas, que inclui a produção de suvenires e camisetas e mesmo de cuecas e calcinhas (gerados para o filme Ai que vida). Não bastasse isso, a visibilidade do filme foi ampliada pela intensa pirataria provocada pela obra, que teria sido capaz de promover uma audiência de mais de 3 milhões de pessoas, fato de difícil comprovação, mesmo que se utilize como referência informação apresentada pela revista Movie $^{17}$.

O certo é que o filme marcou o imaginário da região, graças inclusive à estratégia adotada pelo seu autor, aproveitandose da rede de comunicação mantida por alguns de seus atores e colaboradores, ligados ao rádio, ao jornalismo televisivo ou mesmo a portais, blogs e twitters. ${ }^{18}$ Sem falar do apoio prestado pela televisão comunitária de propriedade de seu pai, a TV Vale do Mearim, de Poção de Pedras, também parte desse sistema regional de abastecimento de notícias. Essa enorme visibilidade proporcionou em 2010 a Cícero uma homenagem pela Câmara dos Vereadores de São Luís, incorporando definitivamente o filme à cultura local: sedenta por afirmação de uma identidade própria e elegendo seus filmes como símbolos dessa procura.

O filme e toda a cinematografia de Cícero são caracterizados como cult. Mais que cult. Que o digam os alunos do $3^{\circ}$ ano do ensino médio da escola Landrí Sales, em São Pedro do Piauí, que, como exercício de aula, interpretam cenas do filme Entre o amor e a razão, com o texto vertido para o inglês e filmado também em locações ${ }^{19}$. É por aí que se nota o impacto de sua obra no universo cultural da região.

Flor de abril é a nova experiência do realizador, ainda centrada nos conflitos entre o campo e a cidade, entre a bondade e a 
maldade, rodada entre o Maranhão e o Piauí, agora já com uma rápida passagem por São Paulo. O filme foi lançado em São Paulo em novembro de 2011, ficou em cartaz uma semana no shopping Riverside, em Teresina, com duas sessões diárias e público de quase mil pessoas, e no Cinesystem Rio Anil, em São Luís, no Maranhão, durante um mês, também com duas sessões e público de 2.500 pessoas. Em junho deste ano, já são 4.000 espectadores, enquanto se prepara algum tipo de lançamento comercial.

Cícero se sofistica, e seu cinema, também, buscando ultrapassar as fronteiras locais. Um nicho de cultura e de potencial de consumo que não pode continuar à margem do sistema e do pensamento cinematográfico brasileiro, como propõe a Carta de Tiradentes e como certamente proporia uma Carta de Teresina. Porque o que Cícero quer, em suas próprias palavras, é entrar no circuito, mostrar as histórias de sua terra e é para isso que ele canaliza toda sua vontade de representação. 


\section{Referências}

CARTA DE TIRADENTES. Tiradentes, 2011. Disponível em: $<$ http://oglobo.globo.com/blogs/cineclube/posts/2011/02/13/cartade-tiradentes-362902.asp>. Acesso em: 4 set. 2011.

CINEMA no Piauí: bases, origens e transformações. Portal Acessepiauí, Teresina, 3 mar. 2010. Disponível em: <http://www. acessepiaui.com.br/cinema/>. Acesso em: 4 set. 2011.

HOLANDA, K. Documentário nordestino: mapeamento, história e análise. São Paulo: Annablume; Fapesp, 2008. 